\title{
2002037
}

\section{Shot Peening and Fatigue Strength of Steels}

Karl-Heinz Lang, Volker Schulze, Otmar Vöhringer

Institut für Werkstoffkunde I, Universität Karlsruhe (TH), Karlsruhe, Germany

\section{Introduction}

Shot peening is a commonly used production process which changes the material state close to the surface. Depending on the material, the material state and the microstructure nearby the surface of the concerning workpiece, the topography, the residual stress state, the workhardening state and the microstructure may be altered. All these changes may influence the fatigue properties of a component more or less significantly. The lifetime may increase if shot peening is performed with optimized peening parameters. For this effect a smoothing of the surface, a workhardening of surface near areas of the material or the introduction of stable residual stresses can be responsible. The greatest lifetime increase may be reached if all three mechanisms act simultaneous. In [1] the characteristics of surface layers produced by shot peening are described in a systematical overview. In principle, the greatest potential for the lifetime increase is ascribed to residual stresses. Residual stresses may alter the cyclic deformation behavior, promote or retard crack initiation, accelerate or decelerate crack propagation, and may be beneficial or detrimental to finite fatigue life and the endurance limit.

The consequences of residual stresses at a concrete application depend strongly on the effects, which are connected with the production of residual stresses like the change of the surface and of the microstructure of surface ncar areas. Furthermore, the stability of the produced residual stresses under the operating conditions and the mechanical properties of the regarded material are relevant. In particular, the material strength is very important. Low strength materials (for example normalized steels or wrought alloys), medium strength materials (for example quenched and at a medium temperature tempered steels or $\gamma^{\prime}$-hardened Ni-base alloys) and high strength materials (for example quenched and at a low temperature tempered steel) have to be distinguished in this context.

In the present paper a systematic overview of the knowledge about the influence of residual stresses - especially of shot peening induced residual stresses - on the different stages of fatigue process and on the endurance limit of different steels and steels in different states will be given using selected examples. A more detailed survey of this topic is given in [2].

\section{Influence of Residual Stresses on the Cyclic Deformation Behavior}

The influence of macro and micro residual stresses produced by shot peening on the cyclic deformation behavior is shown in Fig. 1. As characteristic cyclic deformation curves the plastic strain amplitude from stress controlled push-pull fatigue tests $\left(\mathrm{R}=\sigma_{\min } / \sigma_{\max }=-1\right.$ ) at different stress amplitudes is plotted versus the number of cycles. The behavior of different 

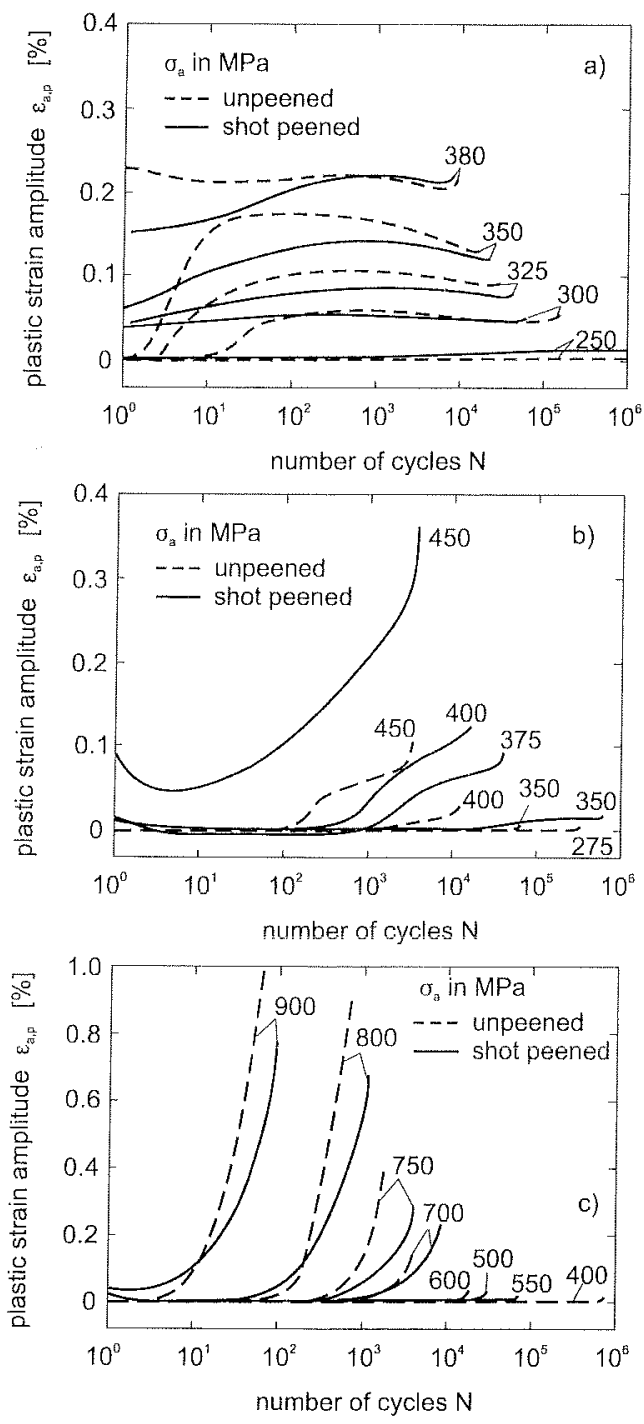

Figure 1: Cyclic deformation for stress controlled pushpull loading of (a) normalized, (b) quenched and tempered $\left(730^{\circ} \mathrm{C} / 2 \mathrm{~h}\right)$, and (c) quenched and tempered $\left(570^{\circ} \mathrm{C} / 2 \mathrm{~h}\right)$ smooth specimens of the steel $42 \mathrm{CrMo} 4$ in unpeened and shot peened conditions. tion in Fig 1b. In this case, the shot peened condition which stresses $\sigma^{\text {Is }}=-530 \mathrm{MPa}$ is characterized for all investigated $\sigma$-values by small measurable plastic strain amplitudes during the first cycle which diminish or disappear first of all with an increasing number of cycles. After a subsequent regime of quasi-elastic behavior, cyclic sof- heat treated smooth specimens of the steel $42 \mathrm{CrMo} 4$ (AISI 4140) are compared in unpeened and in shot peened conditions with compressive residual stresses at the surface $[3,4]$.

In the normalized state (Fig. 1a), the onset of cyclic deformation is different in both conditions, since the shot peened specimens with surface compressive residual stresses $\sigma^{\text {rs }}=-400 \mathrm{MPa}$ show cyclic softening from the first cycle and higher plastic strain amplitudes during the first cycles for stress amplitudes $\sigma_{\mathfrak{a}}$ between $250 \mathrm{MPa}$ and $350 \mathrm{MPa}$. After some numbers of cycles the opposite tendency can be detected and the plastic strain amplitudes of the shot peened conditions are smaller than those of the unpeened material states. However, for the same $\sigma_{a^{-}}$values the plastic strain amplitudes of both conditions approach another at relatively high numbers of cycles. Corresponding results for a quenched and at $730^{\circ} \mathrm{C} / 2 \mathrm{~h}$ tempered $42 \mathrm{CrMo} 4$ are presented in Fig. 1b. In the unpeened condition, the characteristic cyclic deformation behavior of quenched and tempered steels occurs with a quasielastic incubation period which is followed by cyclic softening until crack initiation. After shot peening which generates surface compressive residual stresses $\sigma^{\text {t5 }}=-400 \mathrm{MPa}$, the onset of cyclic softening is shifted to smaller numbers of cycles. Furthermore, it is interesting to note that for identical stress amplitudes and comparable numbers of cycles, the higher plastic strain amplitudes are always measured for the shot peened specimens. Fig. 1c shows a compilation of cyclic deformation curves for another quenched and tempered $\left(570^{\circ} \mathrm{C} / 2 \mathrm{~h}\right) 42 \mathrm{CrMo} 4$ steel with a higher strength compared with the steel condi- 
tening is dominant which yields to lower plastic strain amplitudes and larger numbers of cycles to failure in comparison with the umpeened conditions.

In relatively soft material states, as for example in normalized as well as in quenched and at high temperatures tempered conditions, the consequences of mechanical surface treatments like shot peening or deep rolling on the cyclic deformation behavior are mainly caused by near surface micro residual stresses, i. e. work hardening of the surface layers, because the macro residual stresses are relaxed very soon by cyclic plastic deformation [5-7]. The dislocation structures in the ferrite after the mechanical surface treatment are not stable and change during cyclic loading in energetically more favorable arrangements. The small plastic strain amplitudes of the shot peened or deep rolled conditions and the resulting increase in fatigue life are caused by the restricted mean free path of the mobile dislocations in the work hardened surface layers. In hardened as well as in quenched and at low temperatures tempered conditions, the changes in the cyclic deformation behavior result not only from surface hardening or softening effects but also from the more stable residual stresses.

\section{Influence of Residual Stresses on the Crack Initiation}

Crack initiation occurs as a consequence of microstructural changes in metallic materials during cyclic loading. Different mechanisms are responsible for their formation [e.g. 8]. If it is accepted that for given materials states at comparable load amplitudes increasing amounts of plastic strain amplitudes lead to decreasing numbers of cycles to crack initiation $\mathrm{N}_{\mathrm{i}}$, it follows that residual stresses may extend, shorten or leave the number of cycles unchanged to crack initiation. However, experimental investigations concerning the influence of macro and micro residual stresses on crack initiation are scarce. This is due to the difficulties connected with the observation of the formation and the propagation of small cracks.

A recently published investigation gives a report on the influence of mechanical surface treatments on crack initiation and crack propagation in push-pull loading of steels [9]. In untreated materials, crack initiation normally takes place at positions of high localized slip, e.g. at extrusions and intrusions which are connected with persistent slip bands. However, as

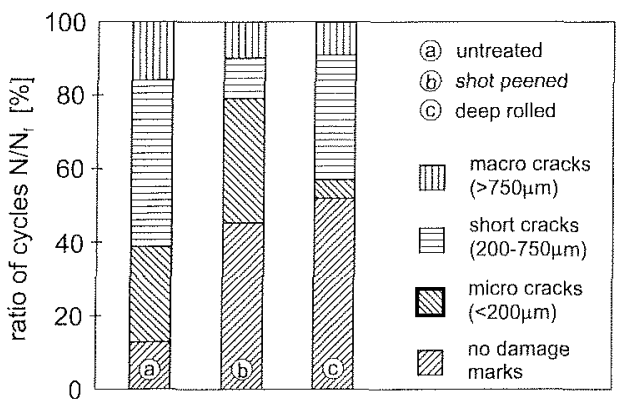

Figure 2: Influence of mechanical surface treatments on the damage evolution of the push-pull loaded austenitic steel AISI $\left.304\left(\sigma_{\mathrm{a}}=320 \mathrm{MPa}, \mathrm{R}=-1, \mathrm{a}\right) \mathrm{N}_{\mathrm{f}}=3859, \mathrm{~b}\right) \mathrm{N}_{\mathrm{f}}=$ $\left.4445, c) N_{f}=20265\right)[9]$ shown in Fig. 2 in shot peened and deep rolled conditions of the austenitic steel AISI 304, crack formation occurs later than in the untreated state due to the consequence of numerous obstacles for slip (dislocations, grain and twin boundaries) in the work hardened surface layer which impede localized slip. In these surface work hardened conditions, no persistent slip band is observed at all. Furthemore, crack propagation is slower than in the untreated state due to the effect of microstructure and compressive residual stresses. Similar results are found in [9] for the normalized steel CK 45 (SAE $1045)$, in $[10]$ for the plain carbon steel 
Ck 80 (SAE 1080) and in $[11,12]$ for a high strength spring steel $50 \mathrm{CrV} 4$ (AISI 6150).

However, in some cases, as reported in [13], the crack initiation time of shot peened

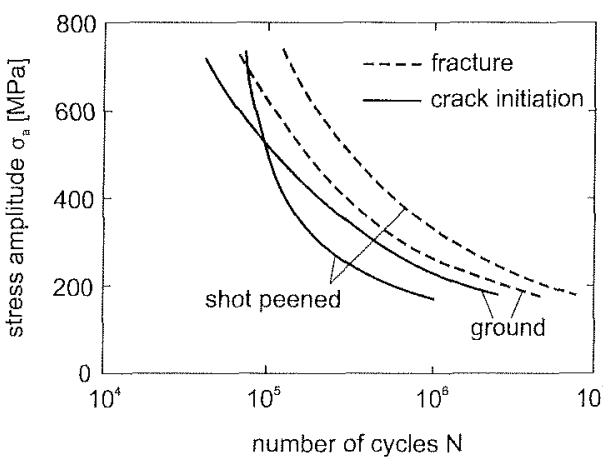

Figure 3: Stress amplitude vs. number of cycles to crack initiation and to failure of a quenched and tempered stecl Ck 45 under bending fatigue loading in sea water [14] specimens is sometimes shorter than that of unpeened ones despite increased lifetimes. One example is given in Fig. 3 for the quenched and tempered steel $\mathrm{Ck}$ 45 (SAE 1045) in the case of bending fatigue tests in sea water [14]. With the exception of high stress amplitudes, the cracks are formed earlier in shot peened specimens than in ground ones. This finding is attributed to an enhanced crack initiation at micro-notches resulting from shot peening which is obviously supported by corrosion pittings in the case of seawater environment. However, the numbers of cycles to failure of the shot peened conditions are higher than that of ground conditions.

\section{Influence of Residual Stresses on the Crack Propagation}

The tip of a propagating crack is surrounded by a typical residual stress field as shown exemplarily in Fig. 4 a for a high strength structural stecl of the Europeani grade S690QL1 $[15,16]$.

A crack was produced by cyclic loading up to a stress intensity range of $\Delta \mathrm{K}_{\mathrm{I}}=$ 47.4 $\mathrm{MPam}^{1 / 2}$. The distribution of the macro rcsidual stress component $\sigma_{y}^{\mathrm{rs}}$, which acts perpendicular to the crack flanks, shows maximum compressive residual stresses of $-350 \mathrm{MPa}$ at the crack tip. The alteration of this distribution after application of 20 overload cycles with an overload ratio $\lambda=2\left(\Delta \mathrm{K}_{\mathrm{I}}=94.8 \mathrm{MPam}^{1 / 2}\right)$ is given in Fig. $4 \mathrm{~b}$. In front of the crack tip, a larger maximum value and a larger area with compressive residual stresses compared to Fig.
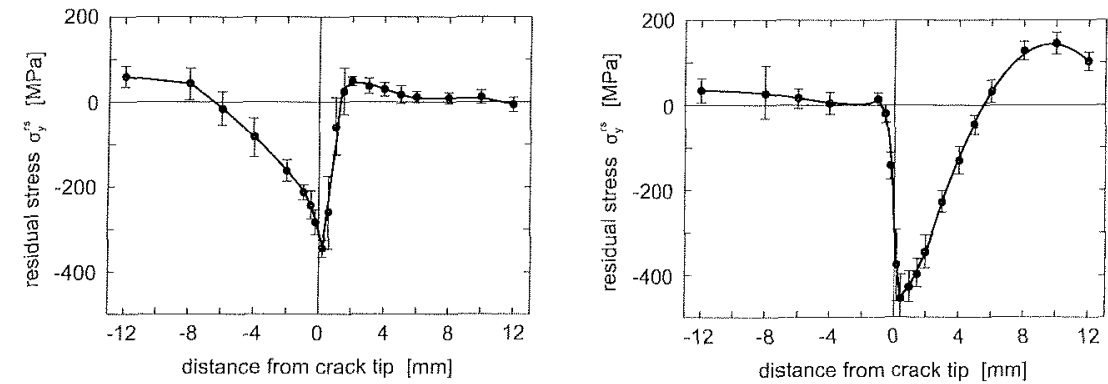

a)

b)

Figure 4: Residual stress component $\sigma_{y}^{\text {fs }}$ vs, distance from crack tip of the steel S690QL1 after a mode l-base load of $\Delta K=47.4 \mathrm{MPani}^{1 / 2}$ (a) and an overload of $\Delta \mathrm{K}=94.8 \mathrm{MPam}^{1 / 2}$ (b) $[15,16]$ 


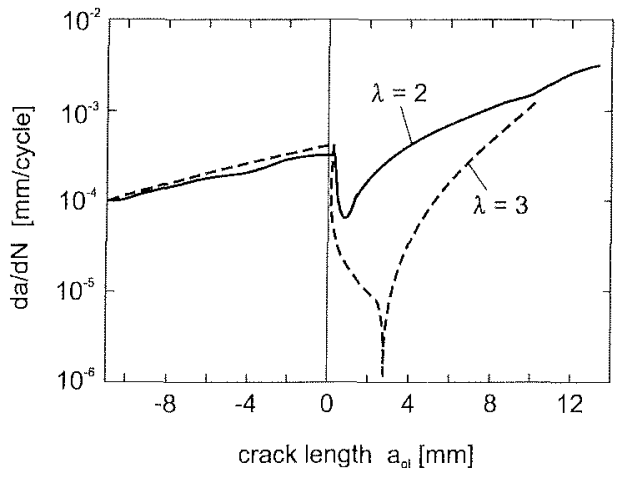

Figure 5: Crack propagation rate $\mathrm{da} / \mathrm{dN}$ vs. crack length $a$ for overloads with $\lambda=2$ and $3[15,16]$

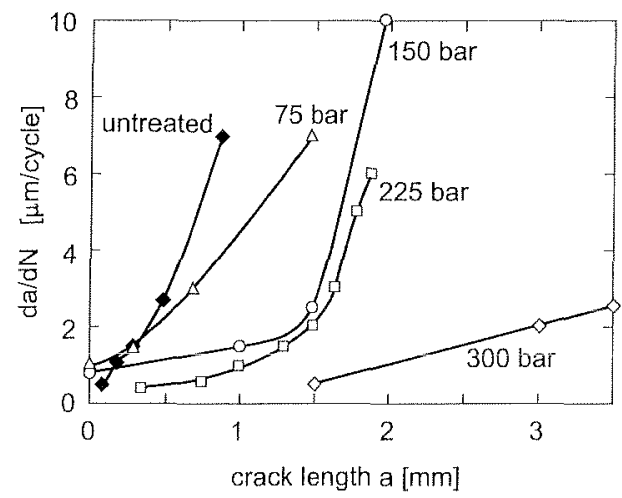

Figure 6: Fatigue crack propagation rates $\mathrm{da} / \mathrm{dN}$ in annealed and with different rolling pressures deep rolled steel AISI 304 (stress amplitude $\sigma_{\mathrm{a}}=320 \mathrm{MPa}$, surface residual stresses $\sigma^{\text {rs }}=-200 \mathrm{MPa}(75$ bar $),-350 \mathrm{MPA}(150$ bar), -400 MPa (225bar), -300 MPa (300 bar)) [18]
$4 \mathrm{a}$ are developed. The influence of different overload cycles on the crack propagation rate is shown in Fig. 5 for $\lambda$ $=2$ and 3 . For both overload ratios a delayed retardation of crack propagation occurs which is more pronounced for $\lambda=$ 3 than for $\lambda=2$ due to the effect of overload induced compressive residual stresses. Thus, by sufficient high overloads, crack arrest can be produced [17].

If a crack propagates into a macro residual stress field, the crack propagation behavior can be considerably influenced by magnitude and distribution of the residual stresses. This is demonstrated in Fig. 6 for differently surface rolled stainless steel AISI 304. Crack velocity is influenced mainly by work hardening and other microstructural changes as well as by residual stresses in the mechanically treated surface layers. The crack propagation rate $\mathrm{da} / \mathrm{dN}$, which was determined by analyzing striations on cracked surfaces increases with increasing rolling pressure and is considerably diminished compared with untreated specimens [18].

For practical purposes, it is very important to know that crack propagation through resiudul siress fields can be described quantitatively by introducing an effective stress intensity range $\Delta \mathrm{K}_{\text {eff }}=$ $\mathrm{K}_{\max }-\mathrm{K}_{\mathrm{op}} . \mathrm{K}_{\max }$ is the stress intensity at maximum loading and $K_{0 p}$ the stress intensity at the loading at which the crack opens. It is important to note that a modeI crack can only grow during that portion of loading cycle where the crack is open. This portion is influenced by the loading conditions itself and the near crack tip residual stress distribution. If the influence of the residual stress contribution on $K_{\text {op }}$ is known, $\Delta K_{\text {eff }}$ can be estimated and used to predict the fatigue crack growth. The validity of this idea could be proved with the crack propagation behavior in the heat-affected zone of welded specimen of SAE 1019 steel specimens in comparison with the one in unwelded specimens [19]. In the welded specimens, the $\mathrm{da} / \mathrm{dN}, \Delta \mathrm{K}$-relations are completely changed. Particularly, for small $\Delta \mathrm{K}$-values the crack propagation behavior is entirely controlled by the welding residual stress state which leads to identical crack propagation rates irrespective of the loading ratio $\mathrm{R}=$ $\sigma_{\min } / \sigma_{\max }$. Using $\Delta \mathrm{K}_{\text {eff }}$ the crack propagation behavior in macro residual stress fields can be quantitatively described if crack propagation data of macro residual stress free materials are available and the residual stress distribution is known. 


\section{Influence of Residual Stresses on the Lifetime Behavior}

S-N curves for alternating bending of normalized $\mathrm{Ck} 45$ steel (SAE 1045) are shown in Fig. 7 [20-23]. The notched specimens had a stress concentration factor $\mathrm{k}_{\mathrm{t}}=2.5$. The stress gradient at the notch root related to the maximum stress (normalized stress gradient $\eta$ ) was $5 \mathrm{~mm}^{-1}$. All data are nominal stress amplitudes and are valid for a failure probability of $50 \%$. The bending fatigue strength was evaluated at an ultimate number of cycles $N_{u}=10^{7}$. Downcut milling and up-cut milling, respectively, generated surface residual stresses of 242 and $-234 \mathrm{MPa}$. The corresponding S-N curves are almost identical. A third batch of specimens was annealed $2 \mathrm{~h}$ at $700^{\circ} \mathrm{C}$ after down cut milling. The annealing results in a reduction of bending fatigue life and bending fatigue strength [20-23].

The alternating bending fatigue strengths of milled smooth and notched specimens with different geometries are plotted in Fig. 8 as a function of the surface residual stresses [20-26].

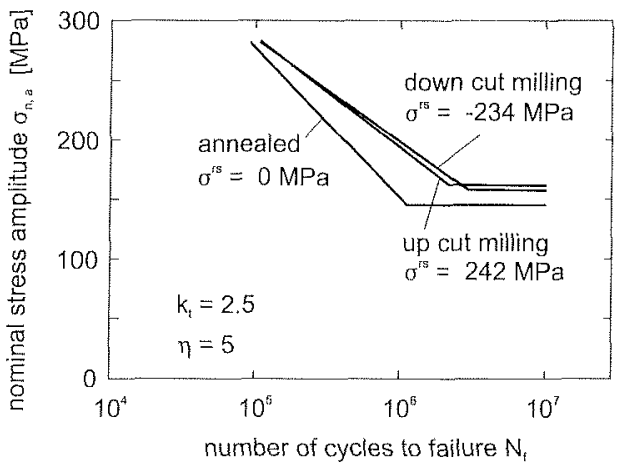

Figure 7: Alternating bending $\mathrm{S}-\mathrm{N}$ curves of notched specimens of normalized plain cabon steel Ck 45 after annealing, down cut milling and up-cut milling [20-23]

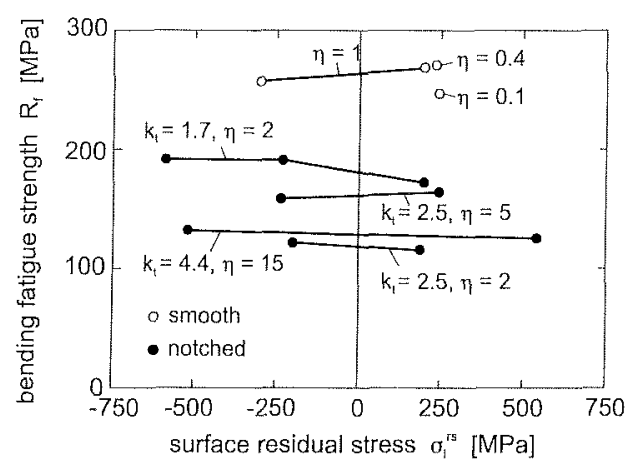

Figure 8: Alternating bending fatigue strength of milled smooth and notched specimens of normalized plain carbon steel CK 45 vs. surface residual stress [20-26]
Again, all data are given for a failure probability of $50 \%$, and the bending fatigue strengths are nominal stress amplitudes at $\mathrm{N}_{\mathrm{n}}=10^{7}$. With increasing stress concentration factor and decreasing stress gradient, the bending fatigue strength decreases. The influence of the stress concentration factor is clearly visible from a comparison of the specimens with the same value $\eta=2 \mathrm{~mm}^{-1}$, but different values $\mathrm{k}_{\mathrm{t}}=1.7$ and 2.5 , respectively. On the other hand, the increase of $\eta$ from 2 to $5 \mathrm{~mm}^{-1}$ at specimens with $\mathrm{k}_{\mathrm{t}}=2.5$ results in a significant increase of bending fatigue strength. It is also interesting to note that specimens with $k_{i}=4.4, \eta=$ $15 \mathrm{~mm}^{-1}$ have a somewhat higher strength than specimens with $\mathrm{k}_{\mathrm{t}}=2.5, \eta=2 \mathrm{~mm}^{-1}$. However, with regard to the residual stress state, there is no significant influence on the bending fatigue strength, even though the range of residual stresses covered comes to more than $1000 \mathrm{MPa}$ regarding specimens with $\mathrm{k}_{\mathrm{t}}=4.4, \eta=$ $15 \mathrm{~mm}^{-1}$. Careful inspection of the hardness of the specimens tested shows that a positive slope of the lines in Fig 8 is not related to the changing (macro) residual stress state, but to different hardness of the specimen and, hence, differences in the micro residual stress state produced by different machining procedures. After correction of the data points given in Fig.8 


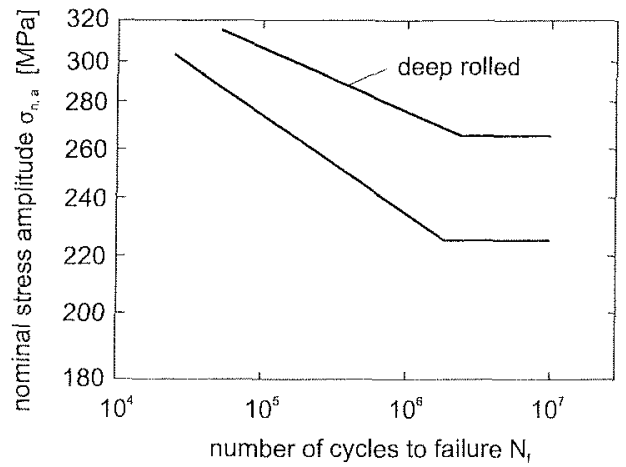

Figure 9: S-N curves of specimens made from normalized Ck15 steel in the as heat treated state and after an additional deep rolling for rotating bending loading [ 27$]$ to the same hardness, it turns out that the bending fatigue strength is hardly changed or slightly diminished at most, if the residual stresses change from compressive ones to tensile ones [23].

$\mathrm{S}-\mathrm{N}$ curves for rotating bending loading of smooth specimens made from normalized Ck 15 steel (SAE 1015) in the as heat treated state and after an additional deep rolling are shown in Fig. 9 [27]. Now, by deep rolling finite fatigue life is increased by one order of magnitude or more, and the rotating bending fatigue strength is increased significantly. The results shown in Fig. 8 and 9 are characteristic for a low strength state of steels.

In Fig. 10, S-N curves which were determined in alternating bending on smooth and notched specimens of quenched and tempered $\left(600^{\circ} \mathrm{C} / 2 \mathrm{~h}\right) \mathrm{Ck} 45$ steel (SAE 1045) as a typical representative of medium strength state of steels are shown [20-23]. Again all data are valid for a failure probability of $50 \%$ and $\mathrm{N}_{u}=$ $10^{7}$. The S-N curves of smooth specimens in the ground state and after an additional shot peening are compared in Fig. 10a. There is a distinct increase of the bending fatigue strength by shot peening, but a rather small influence on finite fatigue life. In Fig. 10b, S-N curves of notched specimens, which were milled, ground and shot peened after grinding are compared. Again, in the range of finite fatigue life, the influence of the different manufacturing processes is almost negligible. The relative increase of the bending fatigue strength by shot peening is more pronounced compared to smooth specimens. It is interesting to note that milled specimens have a higher bending fatigue strength than ground ones, even though they have lower compressive residual stresses $(-159 \mathrm{MPa})$ at the surface than the latter ones $(-221 \mathrm{MPa})$.
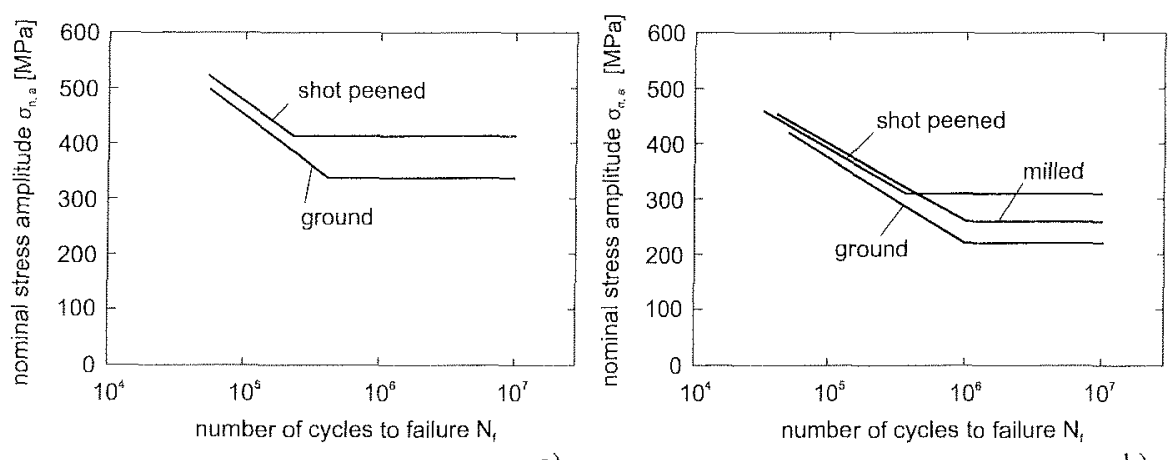

a)

b)

Figure 10: Alternating bending $\mathrm{S}-\mathrm{N}$ curves of specimens made from quenched and tempered $\left(600^{\circ} \mathrm{C} / 2 \mathrm{~h}\right) \mathrm{Ck} 45$ steel a) Smooth specimens after grinding and after additional shot peening. b) Notched specimens after milling, grinding and grinding with additional shot peening [20-23] 


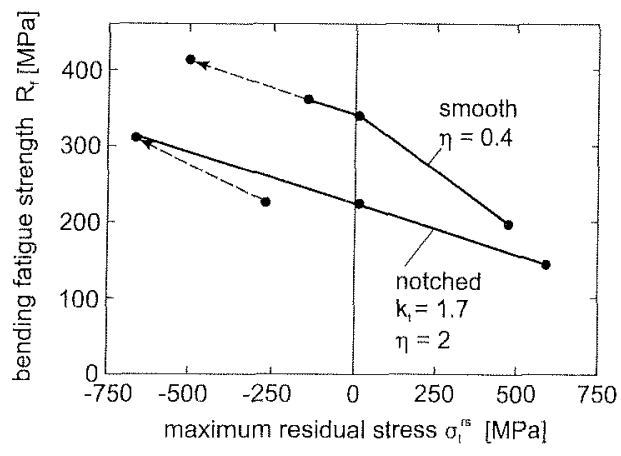

Figure 11: Alternating bending fatigue strength of quenched and tempered $\left(600^{\circ} \mathrm{C} / 2 \mathrm{~h}\right) \mathrm{Ck} 45 \mathrm{steel}$ vs. surface residual stress
In Fig. 11, the alternating bending fatigue strengths evaluated from Fig. 10 are plotted as a function of the surface residual stresses. The arrows mark the shift in bending fatigue strengths and surface residual stresses produced by shot peening. Additionally, data points of ground specimens with negligible or tensile residual stresses are included [2123]. In the case of notched specimens, all data points lie on a common line with the slope -0.154 except for ground specimens with compressive residual stresses at the surface. Regarding smooth specimens, the influence of tensile residual stresses on the bending fatigue strength is much more pronounced than the influence of compressive residual stresses.

In Fig. 12, S-N curves for alternating bending of smooth specimens $\left(\eta=1 \mathrm{~mm}^{-1}\right)$ of blankhardened $16 \mathrm{MnCr} 5$ steel (AISI 5115) determined in the unpeened and various shot peened states including one with electrolytically removed surface layer are shown [28-30]. The corresponding depth distributions of residual stresses are given in Fig. 13. From the comparison of both figures it becomes clear that the surface residual stress is not a suitable parameter for the assessment of the influence of the various treatments on the fatigue behavior.
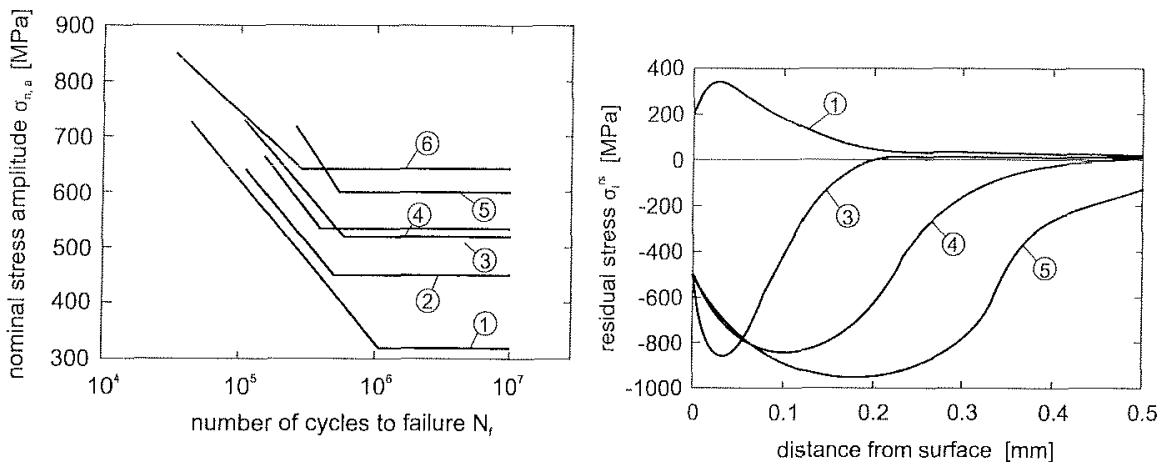

Figure 12: Alternating bending S-N curves of smooth Figure 13: Depth distribution of the residual stress in specimens made from blank-hardened $16 \mathrm{MnCr} 5$ steel specimens made from blank-hardened $16 \mathrm{MnCr} 5$ steel in the as blank-hardened and in additional with in the as blank-hardened (I) and in additional with different conditions shot peened states including one different conditions shot peened state (3,4 and 5) with an subsequently electro-polished surface (1; as corresponding to Fig. 12 (after [28-30])

blank-hardened, 2: shot velocity $v=23 \mathrm{~m} / \mathrm{s}$, coverage

$c=100 \%$, mean diameter of the shot $d=0.6 \mathrm{~mm}, 3: \mathrm{v}$

$=53 \mathrm{~m} / \mathrm{s}, \mathrm{c}=100 \%, \mathrm{~d}=0.3 \mathrm{~mm}, 4: \mathrm{v}=53 \mathrm{~m} / \mathrm{s}, \mathrm{c}=$

$100 \%, d=0.6 \mathrm{~mm}, 5: \mathrm{v}=81 \mathrm{~m} / \mathrm{s}, \mathrm{c}=600 \%, \mathrm{~d}=0.6$

$\mathrm{mm}, 6: \mathrm{v}=53 \mathrm{~m} / \mathrm{s}, \mathrm{c}=100 \%, \mathrm{~d}=0.6 \mathrm{~mm}, 100 \mathrm{um}$

surface layer electrolytically removed) (after $[28-30]$ ) 
The S-N curves of smooth specimens of quenched Ck 45 steel as a typical representative of a high strength state of steels in the ground state and after additional shot peening are compared in Fig. 14a [20-23]. Similar to quenched and tempered specimens (see Fig. 10), shot peening produces a significant increase of the bending fatigue strength. Contrarily to the results of the medium strength steel, however, there is also a very pronounced increase of finite fatigue life, which comes up to one and a half order of magnitude at high stress amplitudes.
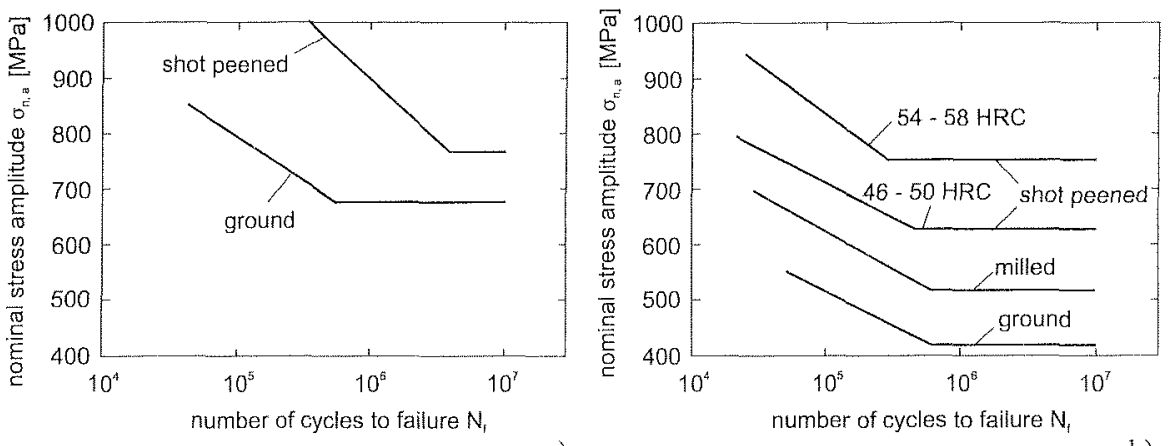

a)

Figure 14: Altenating bending S-N curves of specimens made from quenched $\mathrm{Ck} 45$ steel. a) Smooth specimens after grinding and after additional shot peening. b) Notched specimens after grinding, milling and grinding with additional shot peening with shot of the indicated hatdness [20-23]

The S-N curves of notched specimens of the same steel state after grinding and after additional shot peening with shot of different hardness are shown in Fig. 14b. Compared to smooth specimens, shot peening produces a much stronger increase of the bending fatigue strength. Again, there is also a remarkable increase of finite fatigue life. Additionally, the S-N curve of milled specimen is included. Finite fatigue life and bending fatigue strength of these specimens are lower compared to shot peened ones, even though they contain very high surface compressive residual stresses of $-1200 \mathrm{MPa}$.

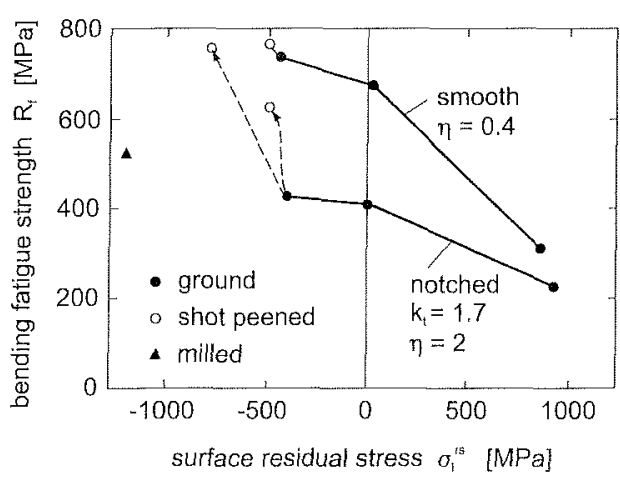

Figure 15: Alternating bending fatigue strength of smooth and notched specimens made from quenched $\mathrm{Ck} 45$ steel with different surface conditions vs. surface residual stress
In Fig. 15, the bending fatigue strength data already plotted in Fig. 14 are complemented by data evaluated from differently ground specimens [20-23]. The arrows mark the shift in bending fatigue strengths and surface residual stresses produced by shot peening. Similar to the discussion of Fig. 12 and 13, it becomes obvious that the magnitude of surface residual stress is not a suitable parameter for the assessment of the influence of shot peening induced residual stresses on the fatigue strength.

One obvious way to account for the influence of (macro-) residual stresses on the fatigue behavior is to treat them as local mean stresses. In doing so, one has to realize that there are several important 


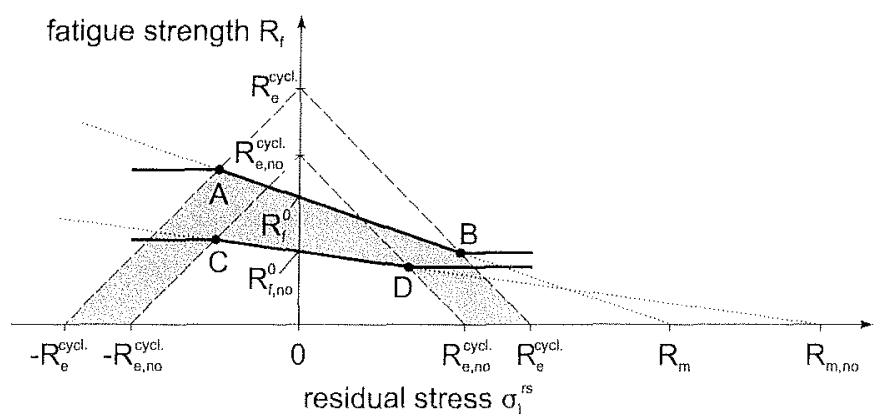

Figure 16: Haigh-diagram: Bending fatigue strength $R_{\mathrm{f}}$ of smooth and notched specimens made from a medium strength steel vs. residual stress (schematically) (after $[13,31]$ )

differences between (loading-) mean stresses and residual stresses [2]. Fig. 16 schematically shows a High-diagram for smooth and notched specimens made from a medium strength steel $[13,31]$. The Goodman-approximation is used to account for the influence of residual stresses on the fatigue strength. If the amount of the minimum stress or the maximum stress in smooth specimens does not exceed the critical stress amplitude $\sigma_{\mathrm{a}, \mathrm{cril}}$ which is a function of the cyclic yield strength [5], the residual stresses do not relax, and the line $\mathrm{AB}$ gives the influence of the residual stress on the fatigue strength. Then, all combinations of residual stress and stress amplitude inside the shaded area do neither result in residual stress relaxation nor in fatigue failure. However, if the amount of the minimum stress or the maximum stress exceeds the critical stress amplitude, it is assumed that the residual stresses relax to the value given by the points $A$ and $B$, respectively, and the fatigue strength remains constant at the value given by these points. In the case of notched specimens, the cyclic yield strength and the notch fatigue strength (both in terms of nominal stress amplitudes) are less than the respective values of smooth specimens. However, the ultimate tensile strength of notched specimens is larger than that of smooth ones in such a material state because of the triaxial stress state in the interior of the notched specimens. Now, the Goodman-relationship holds between points C and D, and residual stress relaxation occurs outside the bright shaded area. From these relationships, it is expected that the residual stress sensitivity of notched specimens is less than that of smooth specimens.

As examples Fig 17 show Haigh-diagrams for smooth and notched specimens made from a high strength steel. In Fig. 17a, the data points give the correlation between the residual stress and the nominal stress amplitude at the surface. In Fig. 17b, the data points give the correlation between the maximum residual stress and the nominal stress amplitude at the locus of the maximum residual stress. In the range of tensile residual stresses, this is always again the surface. The arrows connecting some data points illustrate the residual stress relaxation which occurs during bending fatigue loading. The ultimate tensile strength $R_{m}=$ $1910 \mathrm{MPa}$ of smooth specimens was taken from [23]. The ultimate tensile strength $\mathrm{R}_{\mathrm{m}, \mathrm{no}}$ of notched specimens is unknown, but the value $2000 \mathrm{MPa}$ is reasonable for this high strength material state and the stress concentration factor $1.7[32,33]$. The cyclic yield stresses of smooth and notched specimens are also unknown. However, using results from [20-23] a reasonable borderline for residual stress relaxation can be assumed which indicate the loading at which no residual stress relaxation takes place. The corresponding data points are given in Fig. $17 \mathrm{~b}$ as open square (smooth specimens) and open circle without arrow (notched 
specimens). Assuming, that residual stress relaxation starts at a limiting amount of the minimum or maximum stress irrespective of the fractions of the mean stress and the stress amplitude, one gets the shaded areas in which the residual stresses are stable. These areas are transferred to Fig. 17a, too. The two open circles connected with an arrow illustrate the change of the amount of the surface residual stress (Fig. 17a) and of the minimum stress (Fig. $17 \mathrm{~b}$ ) during the cyclic loading of notched specimens. In milled specimens, there is also some residual stress relaxation as indicated by the triangles connected with an arrow. Obviously, the amounts of the minimum stresses are reduced to a value corresponding to the borderline, confirming this estimation. Extrapolation of this line to zero residual stress yields the values $1785 \mathrm{MPa}$ (smooth specimens) and $1660 \mathrm{MPa}$ (notched specimens), respectively, which are higher than the corresponding yield strengths [23].
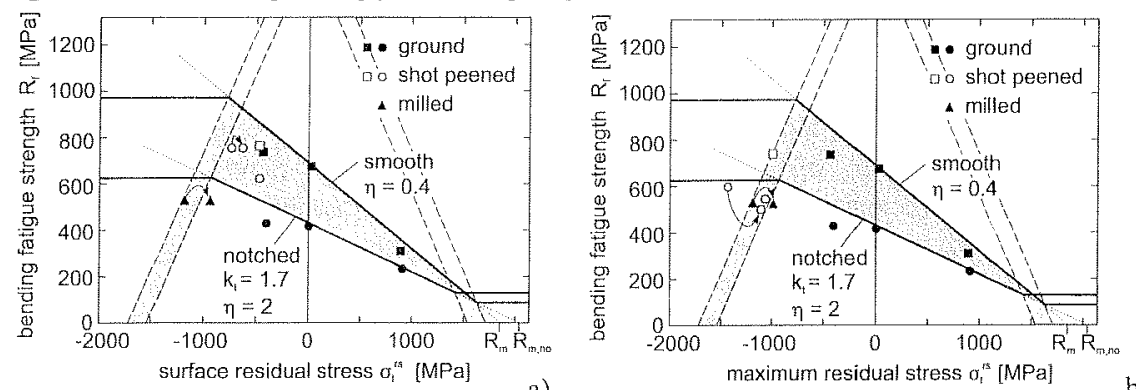

a)

Figure 17: Haigh-diagrams: Bending fatigue strength $R_{f}$ of smooth and notched specimens made from quenched $\mathrm{Ck} 45$ with different surface conditions, a) vs. surface residual stress, b) vs. maximum residual stress

These findings can be understood, if crack initiation and crack propagation or crack arrest are treated separately. This will be possible with the concept of the locally effective fatigue strength which has its origin in $[34,35]$. This concept enables quantitative predictions of the effect of the depth distributions of residual stresses on the locus of crack initiation as well as on the fatigue strength. The basic assumption of the concept is that a crack can only be initiated at or below the surface if the local loading stress exceeds the local fatigue strength. Especially in the case of relatively hard materials, e.g. hardened steels, this concept yields to a good estimation of the corresponding properties. For that purpose, it is necessary to have a good knowledge of the depth distributions of the fatigue strength in the residual stress free condition $R_{\mathrm{f}}^{0}(z)$ as well as of the macro residual stress $\sigma^{\mathrm{Is}}(z)$ and the residual stress sensitivity $m(z)$. The calculation of the locally effective fatigue strength $R_{\mathrm{f}}(z)$ as a function of the distance $z$ from the surface is done by the relationship $R_{\mathrm{f}}(z)=R_{\mathrm{f}}^{0}(z)-m(z) \cdot \sigma^{r s}(z)$, where the residual stress sensitivity $m(z)$ approaches the mean stress sensitivity $M$ of the Goodman relationship if the residual stresses are stable. Then, the residual stress sensitivity is determined approximately by $m(z)=R_{\mathrm{f}}^{0}(z) / R_{m}(z)$ [35]. However, if residual stress relaxation occurs, the residual stress sensitivity $m$ is smaller than the mean stress sensitivity $M$, if the initial residual stress distribution is used [31,35]. However, if the relaxed residual stress distribution is used, the residual stress sensitivity $m$ again approaches the mean stress sensitivity $M$. The depth distributions of the tensile strength $R_{\mathrm{m}}(z)$ and of $R_{\mathrm{f}}^{0}(z)$ can be estimated from appropriate correlations with measured depth distributions of the hardness (see e.g. [36]). This way by the comparison of the depth distribution of local fatigue strength with the depth distribution of the loading both the locus of crack initiation as well as the specimens or component fatigue strength could be estimated (see e.g. [34,35]. 
It is well-known, that in notched specimens or components which are loaded in the range of the fatigue strength, cracks may initiate in the root of sharp notches and may arrest in a certain depth, where the driving force for crack propagation falls below its threshold value because of the steep drop of the loading stress. In most cases, such sharp notches are not relevant for components $[37,38]$. However, in the presence of high residual stresses, the interaction of loading stresses and residual stresses may produce strong gradients of the driving force for crack propagation making crack arrest possible even in notches with low stress concentration factor. On the other hand, in smooth specimens with large compressive residual stresses at and below the surface, crack initiation may occur below the surface because the gradient of loading stresses is small. Then, the question arises whether or not the crack can propagate towards the surface where its propagation is hindered by the residual stress field. Both situations are illustrated by the Haigh-diagrams in Fig. 17. In the case of shot-peened smooth specimens, the fatigue strength falls below the values expected by the Haigh-diagrams, because crack initiation occurs below the surface, where no beneficial effect of the compressive residual stresses is effective. Contrarily, the combination of surface loading stress and surface residual stress occurring at the notch root of specimens with $k_{\mathrm{t}}=1.7$ (Fig. 17a) falls significantly above the corresponding Goodman-line. As already mentioned, this means that cracks initiate at the notch root, but are arrested below the surface.

A crack is arrested, when the driving force for its propagation $\Delta K_{\text {eff }}$ (the range of the effective stress intensity factor) falls below the threshold value $\Delta K_{t h, \text { eff: }}$;

$$
\Delta K_{\mathrm{eff}}=K_{\mathrm{max}}-K_{\mathrm{min}}<\Delta K_{\text {theff }}
$$

In a rough approximation, it is assumed that $K_{o p}$ (the stress intensity factor when the crack opens) equals zero, resulting in

$$
\Delta K_{\mathrm{eff}}(x)=k_{\mathrm{r}} \cdot \Delta \sigma(x) \cdot \sqrt{\pi \cdot a} \cdot Y
$$

for $R=0.1$ and specimens without residual stresses. $\Delta \sigma_{n}$ is the range of the nominal stress. Since compressive residual stresses are present in the specimens investigated, the maximum stress is decreased and the minimum stress becomes less than zero, leading to

$$
\Delta K_{\text {eff }}(x)=\left(k_{1} \cdot \Delta \sigma_{n, \max }+\sigma^{i s}(x) \cdot \sqrt{\pi \cdot a} \cdot Y=K_{\text {max }}(x)\right.
$$

As an example notched specimens of case hardened $16 \mathrm{MnCr} 5$ steel regarded [39]. Therefore, $\Delta K_{\text {thl,efr }}$ also depends on $x$ (the depth below the surface) because of the carbon gradient. Determination of $\Delta K_{\text {th,eff }}$ with CT-specimens machined out of the core region yield values between 6.0 and $6.5 \mathrm{MPa}(\mathrm{m})^{1 / 2}$. For the carburized surface material state a reasonable threshold value of about $4.5 \mathrm{MPa}(\mathrm{m})^{1 / 2}$ was assumed [39]. Concerning the shape of the surface cracks which extend along the notch root, a geometry factor $Y=1.12$ is assumed.

The interaction estimated depth distributions of the residual stresses with the depth distribution of the loading due to a nominal loading stress amplitude $\sigma_{\mathrm{n}, \mathrm{a}}=240 \mathrm{MPa}$ and $\sigma_{\mathrm{n}, \mathrm{a}}=$ $365 \mathrm{MPa}$ - which corresponds to the nominal fatigue strengths $R_{n, f}$ of the unpeened and shot peened specimens [40] - results in the depth distributions of $\Delta K_{\text {eff }}(x)$ shown in Fig. 18 together with the depth distribution of $\Delta K_{\text {th }, \text { ff }}(x)$. Regarding unpeened specimens, $\Delta K_{\text {eff }}(x)$ exceeds $\Delta K_{\text {ll, fff }}(x)$ in a depth of only $15 \mu \mathrm{m}$. Hence, cracks once initiated at oxidized grain boundaries will continue propagation until failure and the fatigue limit is determined by the cyclic loading necessary for crack initiation. For shot peened specimens $\Delta K_{\text {eif }}(x)$ approaches the threshold value between 85 and $100 \mu \mathrm{m}$ below the surface, and cracks may propagate or not. Hence, the fatigue limit corresponds to the boundary between propagating or non-propagating cracks which initiate at the notch root. It is interesting to note that at depths greater than 150 
$\mu \mathrm{m}, \Delta K_{\text {eff }}(x)$ becomes relatively large as a consequence of the high loading amplitude. This means that the significant increase of finite fatigue life by shot peening is entirely based on small crack propagation rates at low distances from surface.
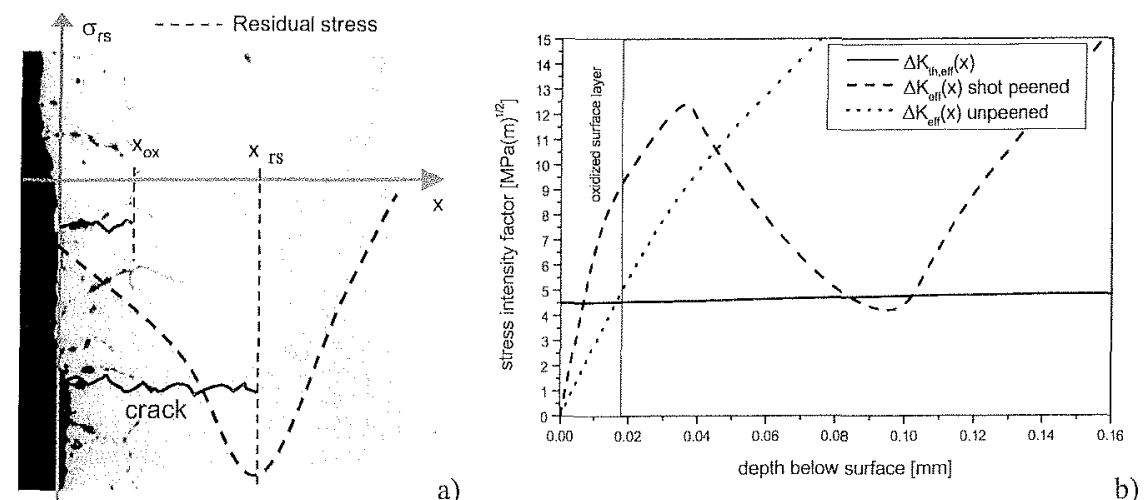

Figure 18: Depth distribution of the residual stresses (a) and local effective stress intensity factors at different distances from surface (b)

\section{Summary}

Regarding residual stresses and fatigue behavior the following conclusions can be drawn:

- In a low strength steel, there will be no or only little influence of macro residual stresses on the fatigue strength $R_{f}$ and on the lifetime in the range of infinite life, because residual stresses relax more or less completely at the latest if the cyclic loading approaches the fatigue strength. A change of the micro residual stress state by work hardening may significantly increase $R_{f}$ since the resistance against cyclic plastic deformation and hence, crack initiation increases.

- In a medium strength steel there is a significant influence of the macro residual stress on $R_{f}$ since only a small part of $\sigma^{r s}$ relaxes during cyclic loading in the range of the fatigue limit. However, in the low cycle fatigue range relaxation becomes more complete with increasing amplitude and the influence of the macro residual stress vanishes. Tensile residual stresses are always detrimental to $\mathrm{R}_{\mathrm{f}}$.

- In high strength steels there is a pronounced influence of residual stresses on $R_{f}$ as well as on the lifetime in the range of infinite life because residual stresses are relative stable during cyclic loading. Stress relaxation in the range of $R_{f}$ only occurs in notched specimens bearing very high compressive residual stresses. Then, the resulting $R_{f}$ is also high and during corresponding cyclic loading, very high magnitudes of the minimum stress occur which leads to some residual stress relaxation. Contrarily, in the range of high tensile residual stresses and cyclic loadings which lead to infinite life or to technically relevant lifetimes the occurring maximum stresses are much lower and no residual stress relaxation is observed even in the range of low cycle fatigue. 


\section{References}

[1] Schulze, V., Characteristics of Surface Layers Produced by Shot Peening. In: Proceedings $8^{\text {th }}$ International Conference on Shot Peening (ICSP 8), 16-20 September 2002, Garmisch-Partenkirchen.

[2] Löhe, D.; Lang, K.-H.; Vöhringer, O., in: Totten, G.; Howes, M.; Inoue, T. (eds.), Handbook of Residual Stress and Deformation. ASM Intemational, Materials Park, OH, USA, 2002, p. 27-53.

[3] Ebenau, A.; Dr.-Ing. Thesis, Universität Karlsruhe (TH), 1989

[4] Ebenal, A.; Eifler, D.; Vöhringer, O; Macherauch, E, in: K. Iida (ed.), Proc. ICSP 4, The Japan Soc. of Precision Engineering, Tokyo, 1990, p. 327-336.

[5] Löhe, D.; Vöhringer, O., in: Totten, G.; Howes, M.; Inoue, T. (eds.), Handbook of Residual Stress and Deformation. ASM Intemational, Materials Park, OH, USA, 2002, p. 54-69.

[6] Kuhn, G, Dr.-Ing. Thesis, Universität Karlsruhe (TH), 1991

[7] Kubn, G.; Hoffmann, J.E.; Eifler, D.; Scholtes, B.; Macherauch, E., in: Fujiwara, H.; Abe, T.; Tanaka, T. (eds.), ICRS 3, Elsevier Applied Science, London, 1991, p. 1294-1301.

[8] Mughrabi, H., in: Ermüdungsverhalten metallischer Werkstoffe. Munz, D. (ed.), DGM-Informationsgesellschaft Verlag, Oberursel, 1985, p. 7-38

[9] Altenberger, I., Dr.--Ing. Thesis, Universität GH Kassel, Forschungsberichte des Instituts für Werkstoffkunde - Metallische Werkstoffe der Universität GH Kassel, Verlag Universitätsbibliothek Kassel, 2000.

[10] Almer, J.D.; Cohen, J.B.; Moran, B., Mater. Sci. Eng A 284, 2000, p. 268-279

[11] Berns, H. Weber, L, in: Residual Stresses in Science and Technology. Macherauch, E.; Hauk, V. (eds.), DGM-Informationsgesellschaft Verlag, Oberursel, 1987, p. 75[-758.

[12] Berns, H.; Weber, L., in: Shot Peening, ICSP 3. Wohlfahrt, H.; Kopp, R.; Vöringer, O., (eds.), DGMInformationsgesellschaft Verlag, Oberursel, 1987, p. 647-654.

[13] B. Scholtes: Eigenspannungen in mechanisch randschichtverformten Werkstoffzuständen, DGM Informationsgesellschaft, Oberursel, 1990.

[14] Herzog, R., Dr.-Ing. Thesis, Universität Braunschweig, 1997. Berichte aus der Werkstofftechnik, Shaker Verlag, Aachen, 1998, ISBN 3-8265-4388-2.

[15] Jägg, S., Dr.-Ing. Thesis, University GH Kassel, 1999, Forschungsberichte aus dem Institut für Werkstoffkunde - Metallische Werkstoffe der Universität GH Kassel, Verlag Universitätsbibliothek Kassel.

[16] Jägg, S.; Scholtes, B., ICRS 5, Linkoeping, Sweden, 1997, p. 1078-1083.

[17] Welsch, E.; Eifler, D.; Scholtes, B.; Macherauch, E., in: Proc. $6^{\text {th }}$ European Conf. on Fracture (ECF 6), Van Elst; Bakker, A. (eds.), Eng. Mater. Adv. Services Ltd (EMAS), Amsterdam, 1986, p. 1303-1320.

[18] Altenbergei, 1.; Scholtes, B.; Matiin, U; Oettel, H., Mater. Sci. Eng. A 264, 19999, p. 1-16.

[19] Kang, K. J.; Song, J. H. ; Earmme, Y. Y, Fatigue Fract. Engng. Mater. Struct. 12, 1989, p. 363-376.

$120]$ Hoffmann, J.E, Löhe, D.; Macherauch, E, in: Wohlfahrt, H.; Kopp, R.; Vöhringer, O. (eds.), Proc. ICSP3, Garmisch-Partenkirchen, DGM Verlag, Oberursel, Germany, 1987, p. 63!-638.

[21] Hoffmann, J.E.; Löhe, D.; Macherauch, E., in: Macherauch, E.; Haw, V. (eds.), Proc, ICRS 1, Vol. 1, DGM Verlag, Oberursel, Germany, 1987, p. 801-808

[22] Hoffmann, J.E.; Eifler, D.; Macherauch, E, in: Macherauch, E.; Hauck, V. (eds.) "Eigenspanungen, Entstehung-Messung-Bewertung", Vol. 2, DGM Verlag, Obenirsel, Germany, 1983, p. 287-300.

[23] Hoffmann, J.E, Dr.-Ing. Thesis, Universität Karlsruhe (TH), 1984.

[24] Syren, B.; Wohlfahrt, H.; Macherauch, E., Arch. Eisenhüttenwesen, Vol. 46, 1975, p. 735-739.

[25] Syren, B.; Wohlfahrt, H.; Macherauch, E., Proc. ${ }^{\text {thd }}$ Int. Conf. Mech. Beh. Mat. (ICM2), Boston, 1976, p. $807-811$.

[26] Syren, B., Dr.-Ing. Thesis, Universität Karlsnuhe (TH), 1975.

[27] Traiser, H.; K.-H. Kloos, K..-H., Z. Werkstofftechnik, Vol. 16, 1985, p. 135-143.

[28] Schreiber, R.; Wohlfahrt, H.; Macherauch, E., Archiv Eisenhüttenwesen, Vol. 49, 1978, p. 207-210

29] Schreiber, R.; Wohlfahrt, H; Macherauch, E., Archiv Eisenhüttenwesen, Vol. 48, 1977, p. 653-657.

[30] Wohlfahrt, H. in: Mechanische Oberflächenbehandlungen, Wohlfahrt, H.; Krull, P. (eds.), Wiley-VCH, Weinheim, Germany, 2000, p. 55-84.

[31] Scholtes, B., in: Structural and Residual Stress Analysis by Nondestructive Methods : Evaluation, Application, Assessment, Hauk, V. (ed.), Elsevier Science B.V., Amsterdam, 1997.

[32] Backfisch, W.; Macherauch, E., Archiv Eisenhuettenwesen Vol. 50,1979, p. 167-171.

[33] Wellinger, K, Dietmann, D., Festigkeitsberechnung, A. Kröner Verlag, Stuttgart, 1969

[34] Macherauch, E.; Wohlfahrt, H., in: Ermüdungsverhalten metallischer Werkstoffe, Munz, D. (ed.), DGMInformationsgesellschaft Verlag, Oberursel, 1985, p. 237-283.

[35] Starker, P.; Macherauch, E.; Wohlfahrt, H., Fatigue of Engng. Mater. Struct., 1, 1987, p. 319-327.

[36] Winderlich, B, Mat. wiss. u. Werkstofftechnik, Vol. 21, 1990, p. 378-389

[37] Kloos, K.-H.; Fuchsbauer, B.; Adelmam, J., J. Fatigue Vol. 9, 1987, p. 35-42.

[38] Kloos, K.-H., in: Kerben und Betriebsfestigkeit, Nowack, H. (ed.), Deutscher Verband für Materialforschung und -prüfung e. V., Berlin, 1989, p. 7-40.

[39] Krug, T.; Lang, K.H.; Löhe, D., in: Blom, A.F, (ed.) Proc. Fatigne 2002, EMAS Ldt. West Midlands, U.K., Volume $2 / 5,2002,955-962$.

[40] Krug, T.; Laue, S.; Lang, K.-H.; Bomas, H.; Löhe, D.; Mayr, P.; FVA-Forschungsheft Nr. 669 , Forschungsvereinigung Antriebstechnik e.V., Frankfurt, Germany, 2001 